\title{
Characterization of the glide planes of the [001] screw dislocations in olivine using electron tomography
}

\author{
Alexandre Mussi · Patrick Cordier · Sylvie Demouchy • \\ Claude Vanmansart
}

Received: 28 November 2013 / Accepted: 26 February 2014 / Published online: 11 March 2014

(c) The Author(s) 2014. This article is published with open access at Springerlink.com

\begin{abstract}
A San Carlos olivine polycrystal has been deformed under uppermost mantle conditions, by compression at $900{ }^{\circ} \mathrm{C}$, at a strain rate of $1.1 \times 10^{-5} \mathrm{~s}^{-1}$, under a confining pressure of $300 \mathrm{MPa}$, using the Paterson press. Transmission electron tomography of dislocations has been performed by scanning transmission electron microscopy, by conventional transmission electron microscopy using the weak-beam dark-field technique, associated with precession or not, in order to determine the glide planes of [001] screw dislocations. This recent technique is the most suitable one since most [001] dislocations exhibit straight screw segments due to the high lattice friction on this character at low temperature. We find that [001] dislocations glide in (100), (010) and $\{110\}$ as already reported, but also more unexpectedly in $\{120\}$ and $\{130\}$. We show that at $900{ }^{\circ} \mathrm{C}$, [001] $\{110\}$ glide is dominant in polycrystals. We have, however, noted and characterized numerous cross-slip events in the specimen.
\end{abstract}

Keywords Olivine - Tomography $\cdot$ Precession · TEM · Dislocation · Glide plane

\section{Introduction}

Being the most abundant and the weakest phase of the Earth's upper mantle, olivine $\left[(\mathrm{Mg}, \mathrm{Fe})_{2} \mathrm{SiO}_{4}\right]$ is the key

A. Mussi $(\bowtie) \cdot$ P. Cordier $\cdot$ C. Vanmansart

Unité Matériaux et Transformations, UMR 8207 CNRS,

Université Lille1, 59655 Villeneuve d'Ascq, France

e-mail: alexandre.mussi@univ-lille1.fr

S. Demouchy

Géoscience Montpellier, UMR 5342 CNRS, Université

Montpellier 2, 34095 Montpellier, France mineral which controls the rheology of the upper mantle. The crystal structure of olivine is orthorhombic $(\mathrm{a} \approx 4.752 \AA, \mathrm{b} \approx 10.193 \AA$ and $\mathrm{c} \approx 5.977 \AA)$, with $\mathrm{a}$ Pbnm space group (Hazen 1976). Plastic deformation of olivine has been the subject of many experimental studies. The dominant slip systems in olivine involve [100] glide at high temperature (i.e. above ca. $1,000{ }^{\circ} \mathrm{C}$ ) and low differential stresses, whereas [001] glide plays a greater role at lower temperature and high differential stresses (Barber et al. 2010). Most studies have addressed the rheology of olivine (or forsterite, the iron-free end member) at temperatures above $1,400{ }^{\circ} \mathrm{C}$ (Bai and Kohlstedt 1992; Darot and Gueguen 1981; Durham and Goetze 1977; Durham et al. 1977; Gueguen 1979; Gueguen and Darot 1982; Jaoul et al. 1979 and Kohlstedt and Goetze 1974), and hence, the deformation mechanisms are reasonably well known in this temperature range. In comparison, less attention has been given to the rheology of olivine in the temperature condition of the uppermost lithospheric mantle (Raleigh 1968; Phakey et al. 1972; Evans and Goetze 1979; Gaboriaud et al. 1981; Raterron et al. 2004; Demouchy et al. 2009; Demouchy et al. 2013a, b), and the deformation mechanisms need to be better constrained in these conditions to support flow laws measured in laboratory conditions (see recent discussion in Demouchy et al. 2013a, b).

From analyses of the slip bands on the surfaces of deformed olivine single crystals, Raleigh (1968) has proposed that glide of [001] dislocations occurs in the $\{110\}$ and (100) planes for temperatures below 1,000 ${ }^{\circ} \mathrm{C}$. Furthermore, Phakey et al. (1972) have conducted an extensive study by transmission electron microscopy (TEM), of the deformation microstructures of single crystals deformed in the low-temperature regime. At $800{ }^{\circ} \mathrm{C}$, the activation of [001] $\{110\}$ was established with some 
suggestions of [001] glide in (100) and (010). Combining the decoration technique (Kohlstedt et al. 1976), with TEM analyses, Gaboriaud et al. (1981) have confirmed that, below $900{ }^{\circ} \mathrm{C}$ (and down to $20^{\circ} \mathrm{C}$ ), the microstructure is essentially composed of straight [001] screw dislocations. Information on the slip planes was inferred from observations on decorated samples suggesting glide of [001] dislocations in (100) and, to a lesser extent, in $\{110\}$ for temperatures higher than $600{ }^{\circ} \mathrm{C}$. So far, TEM-detailed characterizations of slip planes in olivine are very scarce and unfortunately all restricted to characterization of experimentally deformed single crystals of olivine $\left(\mathrm{Fo}_{90}\right)$ or forsterite $\left(\mathrm{Fo}_{100}\right)$. In our study, we provide the characterization of glide planes for the [001] screw dislocation in a deformed olivine aggregate using electron tomography.

For characterization of [001] glide, there is a specific difficulty associated with the fact that, at low temperature, [001] dislocations bear a high lattice friction on screw characters. Then, most of the dislocations are straight screw segments with relatively few non-screw segments, which could allow slip plane determination. To identify the slip plane, one must tilt the specimen to put the plane edge-on. Depending on the orientation, this may require tilt angles that can be high or even not accessible. Alternatively, the stereographic projection originally proposed 175 years ago by Miller (1839) and applied to TEM analyses 40 years ago by Head et al. (1973) can be applied. This method is, however, very time-consuming and very often of very poor accuracy. However, today transmission electron tomography enables the reconstruction of a volume from a series of projected images (called a tilted series). Most often, the reconstructed volumes are obtained using images based on an absorption contrast (Buseck et al. 2001; Arslan et al. 2006; Midgley and Dunin-Borkowski 2009). The more the angular range increases, the more the omitted volume (missing wedge) decreases, and the more the reconstruction volume quality rises. The first successful transmission electron tomography of dislocations has been performed in a semiconductor $(\mathrm{GaN})$ by Barnard et al. (2006a, b, 2010). The reconstruction has been performed based on images obtained in conventional TEM (diffraction contrast mode) using the weak-beam dark-field (WBDF) technique. Under these imaging conditions, the contrast is extremely sensitive to the specimen orientation with respect to the electron beam. The deviation from exact Bragg conditions $\left(\mathrm{s}_{\mathrm{g}}\right)$ has to be kept strictly constant for the entire tilted series. To reach these conditions, the tilt axis has to be perfectly aligned, with a precision of the order of a tenth of a degree, with the diffraction vector used to image the dislocations. However, the contrast of dislocation is usually oscillating in WBDF (i.e. when dislocation lines are inclined within the thin foil), and the background is always inhomogeneous due to the occurrence of thickness fringes and bend contours. Consequently, despite a good signal-to-noise ratio, it is necessary to carefully filter each image to succeed in correctly reconstructing the dislocations. Unfortunately, this image processing results in a loss of information. Scanning transmission electron microscopy (STEM) has also been used to image crystal defects (Phillips et al. 2011a, b) and to perform electron tomography (Sharp et al. 2008; Tanaka et al. 2008a, b). The STEM mode allows to obtain a homogeneous background, but, except for field emission guns (FEG), the signal-to-noise ratio is weak. A recent study from Rebled et al. (2011) associates tomography with precession. The precession technique reduces bend contours, dislocation oscillating contrasts and thickness fringes while keeping a good signal-to-noise ratio.

In the present study, we show that dislocation transmission electron tomography associated with precession significantly expands the possibility to characterize glide planes in deformed minerals. We present an application on the characterization of glide planes of [001] dislocations in a polycrystal of olivine deformed at $900{ }^{\circ} \mathrm{C}, 300 \mathrm{MPa}$ (Demouchy et al. 2013a, b, 2014).

\section{Experimental details}

Sample and deformation experiment

A polycrystal of San Carlos olivine has been deformed at $900{ }^{\circ} \mathrm{C}$ under a confining pressure of $300 \mathrm{MPa}$, at a $1.1 \times 10^{-5} \mathrm{~s}^{-1}$ strain rate using a gas medium high pressure and high temperature deformation apparatus (Paterson 1970, 1990). The fine-grained olivine powder was first cold pressed at room pressure then sintered at high temperature $\left(1,250{ }^{\circ} \mathrm{C}\right)$ and high pressure (300 MPa) for $3 \mathrm{~h}$ before temperature was cooled down, and stabilized to $900{ }^{\circ} \mathrm{C}$ prior to tri-axial deformation. The starting polycrystal olivine has cylindrical geometry of ca. $1 \mathrm{~cm}^{3}$ (the starting $\mathrm{Ni}$ sleeve is $9.45 \mathrm{~mm}$ in diameter and $20.03 \mathrm{~mm}$ long). The details of the geometry of the experimental set-up can be found in previous studies (Paterson 1990; Chen et al. 2006; Demouchy 2010; Demouchy et al. 2012, 2013a, b). At high temperature, to buffer oxygen fugacity to values relevant of the upper most mantle (McCammon 2005), a pure nickel film has been integrated between the polycrystal olivine and the outer iron jacket. A hydrostatic pressure of $300 \mathrm{MPa}$ of argon gas (inert gas) and a compressive deviatoric stress is applied to deform the sample at a constant displacement rate.

Transmission electron tomography

To prepare the TEM thin foils, a slice containing the compression axis was cut and mechanically polished to a thickness of ca. $30 \mu \mathrm{m}$. Electron transparency was further obtained by 
ion milling (in a Gatan ${ }^{\circledR}$ DuoMillTM Model 600). To insure electron conduction, a thin carbon film has been coated on the thin foil. A FEI ${ }^{\circledR}$ Tecnaï $\mathrm{G}^{2} 20$ Twin microscope, operating at $200 \mathrm{kV}$ with $\mathrm{a} \mathrm{LaB}_{6}$ filament, was used at the TEM facility of the University of Lille. Six tilted series were acquired every $2^{\circ}$, in a double tilt sample holder (the acquisition conditions are summarized in Table 1). During this study, we have used different acquisition methods: WBDF, STEM and WBDF associated with precession. As the contrast is very weak in WBDF, automatic focus and alignment are inefficient. Consequently, the tilted series are acquired and aligned manually to achieve pixel precision. To improve the background homogeneity, each image is filtered using the ImageJ software, with a polynomial fit. Then, a convolution of each image with a Kernel matrix is performed to increase the dislocation contrast (Barnard et al. 2010). Finally, the reconstructed volumes are obtained using the Gatan ${ }^{\circledR}$ 3D reconstruction software with the simultaneous iterative reconstruction technique (SIRT) algorithm (Penczek et al. 1992).

\section{Results}

The size of the studied grains ranges between 5 and $13 \mu \mathrm{m}$ with analysed zones being slightly smaller $(2-4 \mu \mathrm{m})$.
Table 1 Acquisition conditions for each grain

\begin{tabular}{|c|c|c|c|}
\hline & $\begin{array}{l}\text { Microscope } \\
\text { modes }\end{array}$ & $\begin{array}{l}\text { Diffraction } \\
\text { vector }\end{array}$ & Tilted series ranges \\
\hline Grain I & STEM & 004 & $-56^{\circ}$ to $58^{\circ}$ every $2^{\circ}$ \\
\hline Grain II & WBDF & 004 & $-60^{\circ}$ to $50^{\circ}$ every $2^{\circ}$ \\
\hline Grain III & WBDF & 004 & $-56^{\circ}$ to $50^{\circ}$ every $2^{\circ}$ \\
\hline Grain IV & $\begin{array}{l}\text { WBDF + } \\
\text { precession }\end{array}$ & 222 & $-56^{\circ}$ to $50^{\circ}$ every $2^{\circ}$ \\
\hline Grain V & $\begin{array}{l}\text { WBDF }+ \\
\text { precession }\end{array}$ & 222 & $-56^{\circ}$ to $46^{\circ}$ every $2^{\circ}$ \\
\hline Grain VI & $\begin{array}{l}\text { WBDF }+ \\
\text { precession }\end{array}$ & 222 & $-54^{\circ}$ to $52^{\circ}$ every $2^{\circ}$ \\
\hline
\end{tabular}

Considering the tomographic reconstructed volumes, a typical dislocation density of $10^{13} \mathrm{~m}^{-2}$ was measured.

After the reconstructions of the centred filtered tilted series, the tomographic volumes are precisely oriented in order to place specific planes [e.g. (100), (010), $\{110\}$, $\{120\},\{130\},\{140\},\{210\},\{310\}$ and $\{410\}]$ edge-on. An example of slip plane determination of a [001] dislocation (labelled "I") is shown on Fig. 1. A marked curvature is observed when the dislocation is viewed along the [410] zone axis (Fig. 1a). When the same dislocation "I" is viewed along the $[\overline{1} 10]$ zone axis, it appears as a
Fig. 1 [001] dislocation in (110). Reconstructed volume of a part of grain III (see the acquisition conditions in Table 1 and the method in the main text). a The [001] dislocation labelled "I" (indicated by a white arrow) is strongly curved when seen along the [410] zone axis; $\mathbf{b}$ the glide plane of "I" is nearly edge-on along the $[\overline{1} 20]$ zone axis, since this dislocation exhibits only a slight curvature along this orientation; $\mathbf{c}$ seen along the $[\overline{1} 10]$ zone axis, dislocation "I" appears as a straight line, showing that it is contained in the (110) plane which is edge-on (here for a tilt angle of $116^{\circ}$ ); d dislocation "I" seen along the $[\overline{2} 10]$ zone axis; e dislocation "I" is strongly curved, in the opposite direction to (a), along the $[\overline{4} \overline{1} 0]$ zone axis
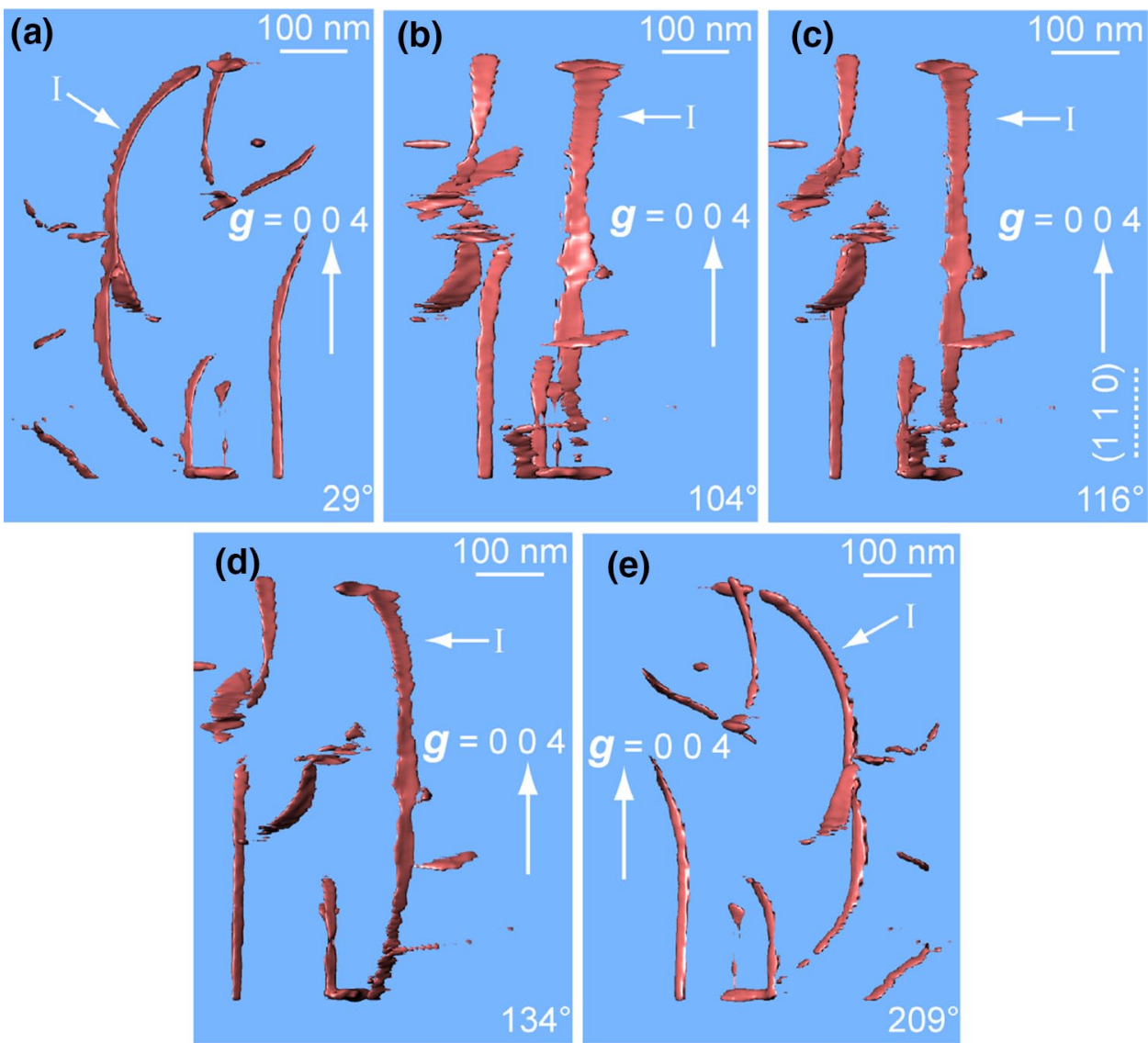
straight line parallel to the (110) plane (Fig. 1c). Further rotation of the reconstructed volume along the tilt axis shows the same curvature with another maximum when the $[\overline{4} \overline{1} 0]$ zone axis is reached (Fig. 1e). The glide plane of dislocation "I" is almost in the plane of the micrograph.

Several dislocations exhibit lines made of segments which belong to several planes. Figure 2 illustrates such a case with a [001] dislocation constituted of two segments (labelled "1" and "2"). The reconstructed tomographic volume has been obtained from images taken with the 004 diffraction vector. The segment " 1 " appears straight when the reconstructed volume is tilted in such a way that the $(1 \overline{1} 0)$ plane is edge-on, i.e. for a tilt angle of approximately $121^{\circ}$ (Fig. 2e). For the segment "2" to appear linear, the reconstructed volume has to be tilted to ca. $71^{\circ}$ in order to put the (110) plane edge-on (Fig. 2c). The line of this dislocation belongs to the $(1 \overline{1} 0)$ and to the (110) planes. This determination would have been beyond reach by a standard tilting experiment.

Beyond the usual (100), (010) and $\{110\}$ glide planes that were expected from the literature, we have characterized several other planes containing [001] dislocations. Dislocation labelled "II" on Fig. 3a is highly curved when the reconstructed volume is observed along the $[\overline{2} 10]$ zone axis, but it is seen as a straight line when the $(120)$ plane is edge-on (Fig. 3b). Similarly, Fig. 4 shows that the dislocation labelled "III" glides on the (130) plane.

The number of dislocation segments observed in each glide plane characterized in this study is summarized in Table 2. It is worth noticing that a majority of $\{110\}$ glide planes are characterized in each grain. Furthermore, Table 3 recapitulates all the observations of dislocations lines belonging to more than one single glide plane.
Fig. 2 Cross-slip of a [001] dislocation: a micrograph of grain III, with the conditions indicated in Table 1 (the grain is imaged along the [100] zone axis); b corresponding reconstructed volume seen along the same direction; it is successively tilted to be viewed along the $[1 \overline{1} 0]$ zone axis (tilt of $71^{\circ}$ in c); along the $[0 \overline{1} 0]$ zone axis (tilt of $96^{\circ}$ in d); along the $[110]$ zone axis (tilt of $121^{\circ}$ in e); and along the $[\overline{100}]$ zone axis (tilt of $-174^{\circ}$ in $\mathbf{f}$ ). One segment of the dislocation labelled " 1 " lies in the (110) plane (see e), whereas the other segment of the dislocation labelled " 2 " lies in (110) (see c)
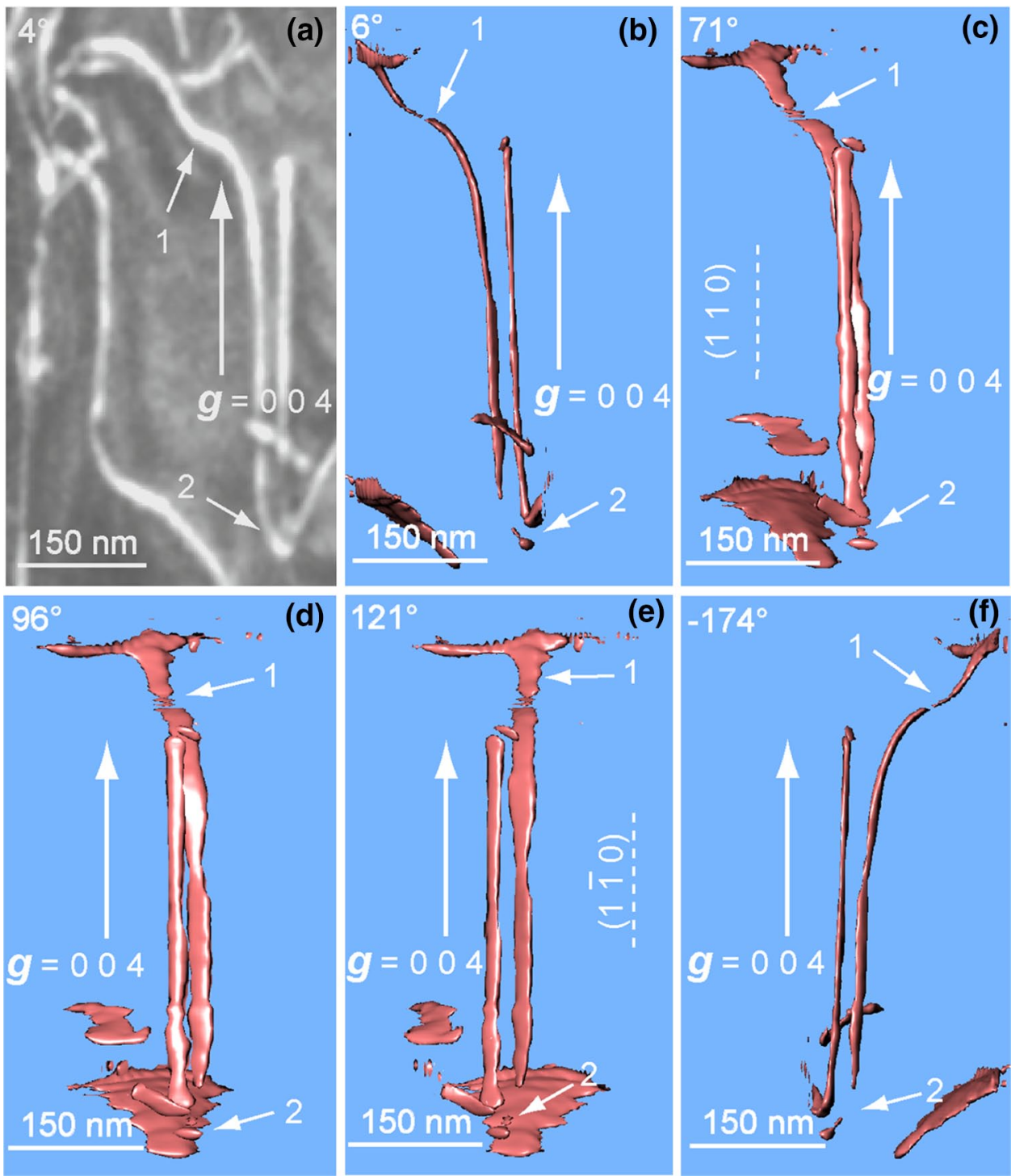
Fig. 3 [001] dislocation lying in $(1 \overline{2} 0)$ (3D reconstruction volume of a part of grain III and acquisition conditions in Table 1): The [001] dislocation (labelled "II" and indicated by a white arrow) is seen along the $[210]$ zone axis (a); along the [210] zone axis (tilt angle $132^{\circ}$ ), where it appears as a straight line parallel to $(1 \overline{2} 0)(\mathbf{b})$; and along the $[\overline{2} 10]$ zone axis (tilt of $42^{\circ}$ in c)
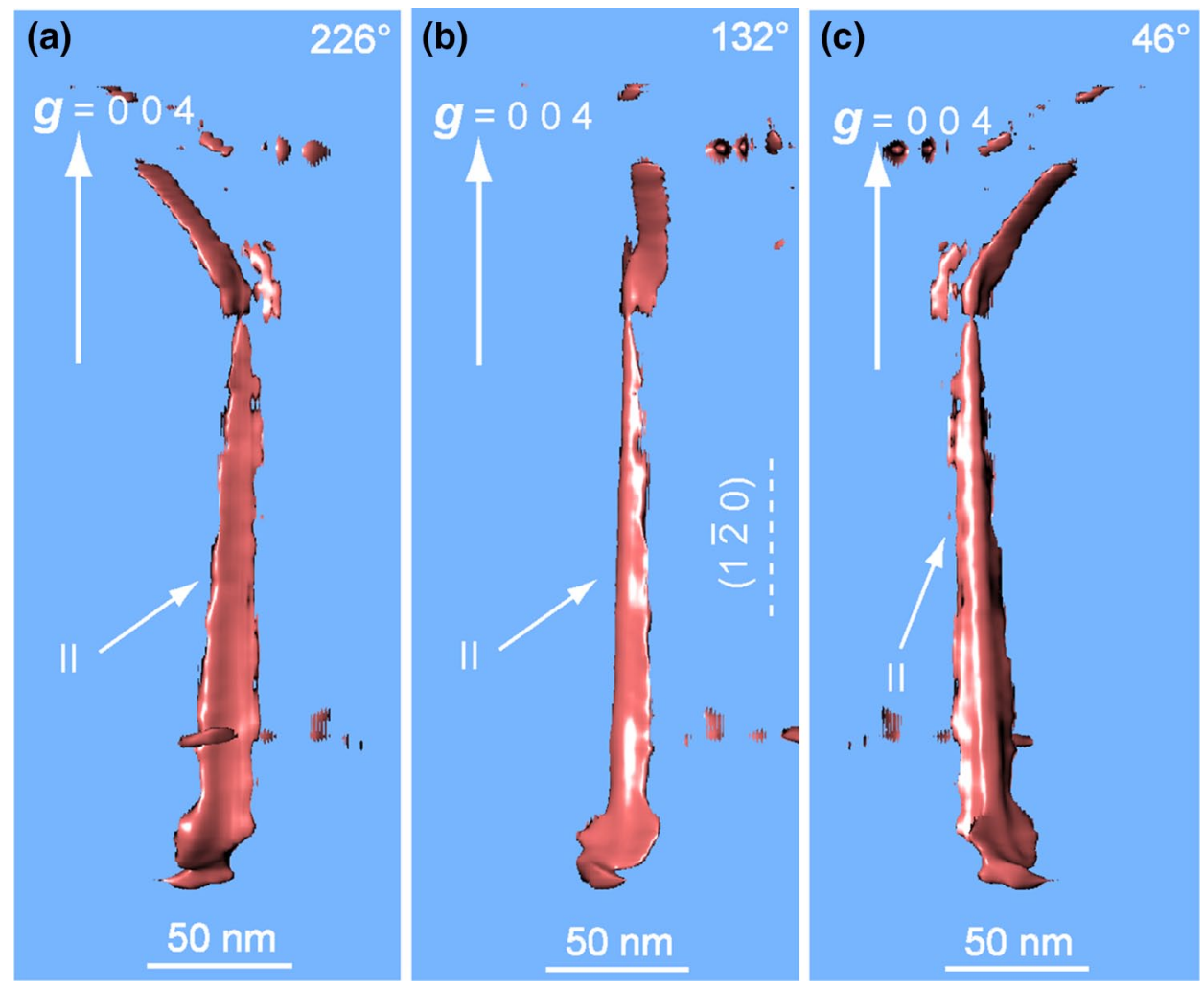

Fig. 4 [001] dislocation, from grain III, lying in (130). The [001] dislocation labelled "III" (indicated by a white arrow) is viewed along the [210] zone axis (a); the $[4 \overline{1} 0]$ zone axis (b); the $[3 \overline{1} 0]$ zone axis $(\mathbf{c})$, the $[2 \overline{1} 0]$ zone axis (d), and the $[\overline{2} \overline{1} 0]$ zone axis (e). This dislocation belongs to the (130) plane since it appears as a straight line parallel to this plane, in (c)
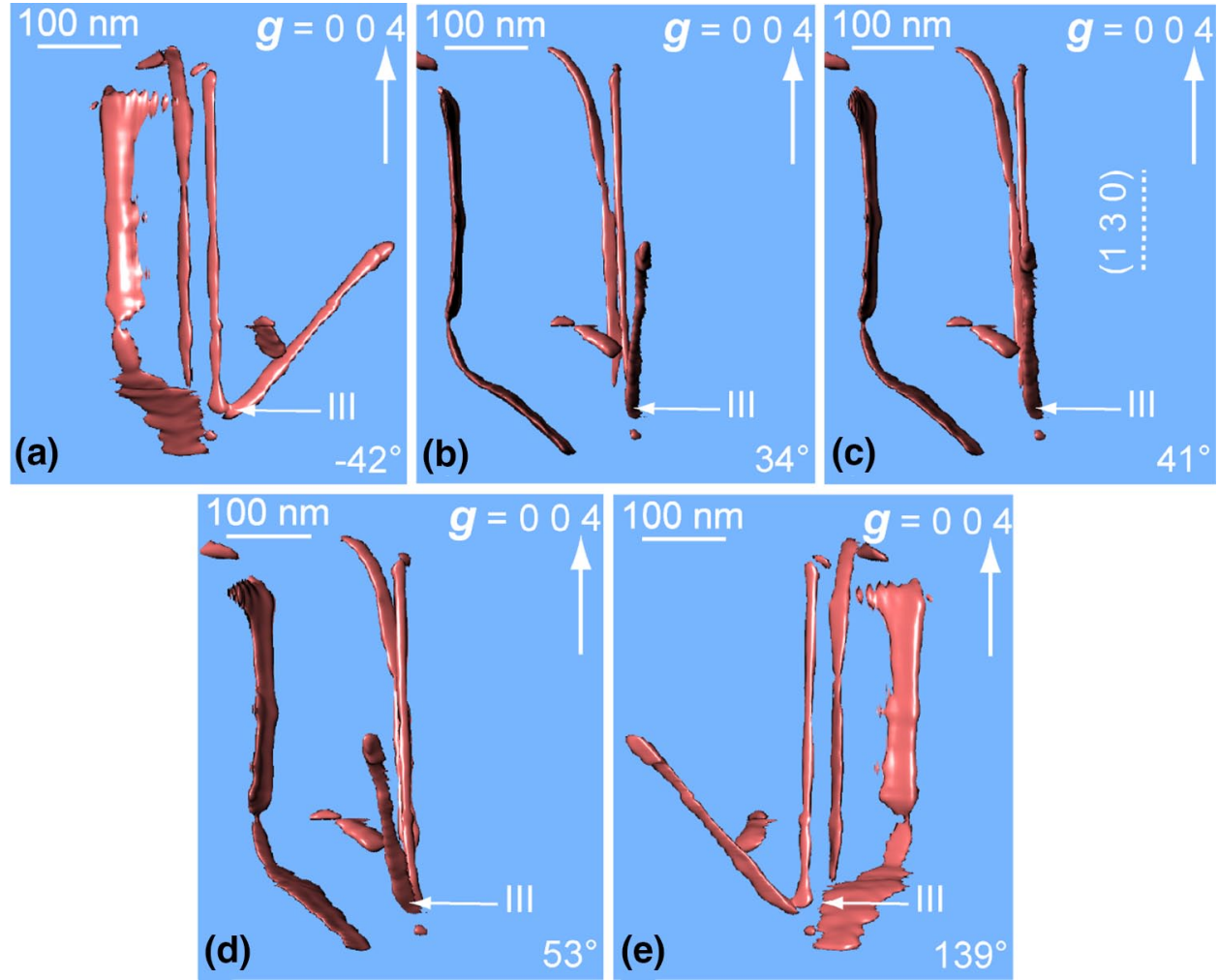
Table 2 Occurrence of each glide plane

\begin{tabular}{lllllllr}
\hline Glide planes/grain & Grain I & Grain II & Grain III & Grain IV & Grain V & Grain VI & Total \\
\hline$(100)$ & 3 & 2 & 2 & 0 & 0 & 0 & 7 \\
$(010)$ & 2 & 1 & 2 & 2 & 1 & 2 & 10 \\
$\{110\}$ & 7 & 6 & 13 & 4 & 2 & 0 & 32 \\
$\{120\}$ & 0 & 1 & 2 & 0 & 2 & 0 & 5 \\
$\{130\}$ & 0 & 1 & 2 & 1 & 1 & 0 & 5 \\
\hline
\end{tabular}

Table 3 Observation of cross-slip events

\begin{tabular}{llll}
\hline Dislocations showing cross-slip & \multicolumn{3}{l}{ Dislocation segments } \\
\cline { 2 - 3 } & 1 & 2 & 3 \\
\hline Dislocation 1 in grain II & $(100)$ & $(110)$ & $(1 \overline{1} 0)$ \\
Dislocation 2 in grain II & $(110)$ & $(130)$ & \\
Dislocation in grain III & $(110)$ & $(1 \overline{1} 0)$ & \\
\hline
\end{tabular}

\section{Discussion}

Plastic deformation of olivine at $900{ }^{\circ} \mathrm{C}$ corresponds to a low-temperature regime where [001] glide is activated with a strong lattice friction on screw dislocations (Durinck et al. 2007; Demouchy et al. 2013a, b). Fast non-screw segments are thus less represented in the deformed grains. Their characterization is, however, critical to identify the slip planes of [001] dislocations. In this study, we have used the following approach: first, dislocation lines containing nonscrew segments and exhibiting significant curvatures were chosen. Then, the reconstructed volumes were tilted until the dislocation line appears as a straight line. Finally, the normal to the straight line identifies the slip plane. Subsequently, the reconstructed volume allows to reach any orientation which expands significantly the number of lines
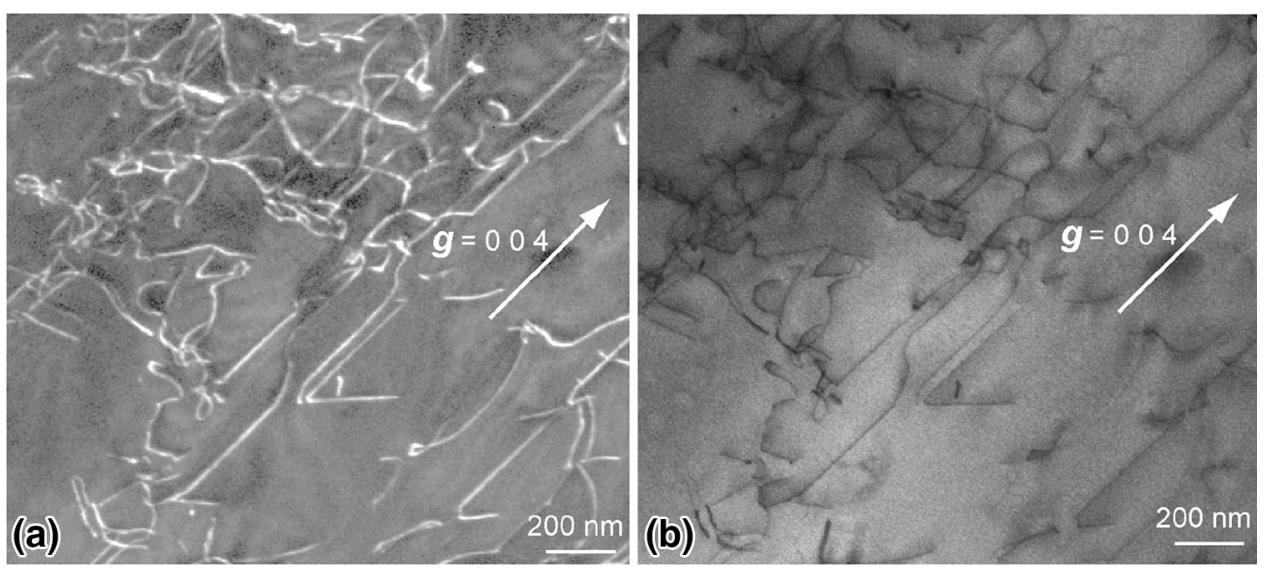

Fig. 5 Comparison between a WBDF micrograph and the STEM corresponding micrograph: a WBDF image obtained with the g:004 diffraction vector (the dislocation contrast width is $11.7 \mathrm{~nm}$ and the dislocation signal-to-noise ratio is $113 \%$ ); b corresponding weak- defects that can be characterized. Indeed, about sixty glide planes have been characterized in the present study. As an example, Fig. 2c shows that a tilt angle of $71^{\circ}$ is necessary to set the (110) plane edge-on. Under this orientation condition, the observed reconstructed volume is in the missing wedge of the tilted series.

Here, we present the technical justifications which validate our approach. We recall that dislocation transmission electron tomography has been performed using several techniques.

The WBDF technique gives a high dislocation signal-tonoise ratio, but generally the background contrast and the dislocation contrast are not homogeneous (Barnard et al. 2006a, b, 2010). In order to reconstruct dislocation tomographic volumes with a sufficiently high quality, the analysed region has to exhibit a relatively constant orientation and thickness.

The STEM technique gives a more homogeneous contrast for the background. Thanks to the principle of reciprocity, dislocations can be well imaged by diffraction contrast in this mode. Its principle consists in a correspondence between conventional TEM (CTEM) and STEM. To achieve conditions equivalent to CTEM, STEM conditions must involve a small collecting angle (close to a parallel beam). For that purpose, we have increased the camera length and decreased the size of the condenser aperture.

beam bright-field STEM image obtained with the g:004 diffraction vector, a camera length of $200 \mathrm{~mm}$, a spot size of $2 \mathrm{~nm}$ and a condenser aperture of $20 \mu \mathrm{m}$ (the dislocation contrast width is $9.5 \mathrm{~nm}$ but the dislocation signal-to-noise ratio is only $18 \%$ ) 
Nevertheless, the diffraction disc has to be fully positioned on the dark-field detector without any overlapping with the bright-field detector. In our study, with a $\mathrm{FEI}^{\circledR}$ Tecnaï $\mathrm{G}^{2} 20$ Twin $\mathrm{LaB}_{6} 200 \mathrm{kV}$ S/TEM, the best conditions are obtained with a camera length of $200 \mathrm{~mm}$ and a condenser aperture of $20 \mu \mathrm{m}$ (Fig. 5b). These conditions are not so far from the conditions of Phillips et al. (2011a, b). Indeed, the authors have obtained an optimal camera length of 163 mm, with a FEI ${ }^{\circledR}$ Tecnai F20 FEG 200 kV S/TEM. Figure 5 shows that using our best STEM conditions, the dislocation are observed with a comparable resolution (contrast width $11.7 \mathrm{~nm}$ in WBDF conditions and $9.5 \mathrm{~nm}$ in STEM conditions), but with a signal-to-noise ratio approximately
6 times lower than in WBDF (113\% in WBDF conditions and $18 \%$ in STEM conditions). It is expected that the use of a FEG would improve this aspect.

In our study, the best compromise between contrast homogeneity and signal-to-noise ratio is obtained when precession is combined with the WBDF technique. Indeed, the WBDF technique provides a high signal-to-noise ratio for dislocations, and the precession decreases heterogeneities along the dislocations lines (oscillating contrast) and in the background (Rebled et al. 2011). This technique reduces and often eliminates bend contours. Precession modifies and integrates $s_{\mathrm{g}}$, which removes or attenuates the thickness fringes as well as the oscillating contrast of
Fig. 6 Comparison between a WBDF micrograph and the corresponding WBDF micrograph associated with precession: a WBDF image obtained with the $2 \overline{2} 2$ diffraction vector (dislocation oscillating contrast and thickness fringes are marked); b corresponding WBDF micrograph associated with a $0.1^{\circ}$ precession angle (dislocation oscillating contrast and thickness fringes have disappeared)

Fig. 7 Effect of a kernel filtering: a WBDF image obtained with the $2 \overline{2} 2$ diffraction vector associated with a $0.1^{\circ}$ precession angle (reconstructed volume of a part of grain IV with the conditions specified in Table 1); $\mathbf{b}$ corresponding WBDF micrograph filtered with a kernel (the dislocation contrast is enhanced); $\mathbf{c}$ electron transmission tomographic volume resulting from $\mathbf{a} ; \mathbf{d}$ electron transmission tomographic volume resulting from $\mathbf{b}$ (the kernel filtering has kept most of the dislocation population details)
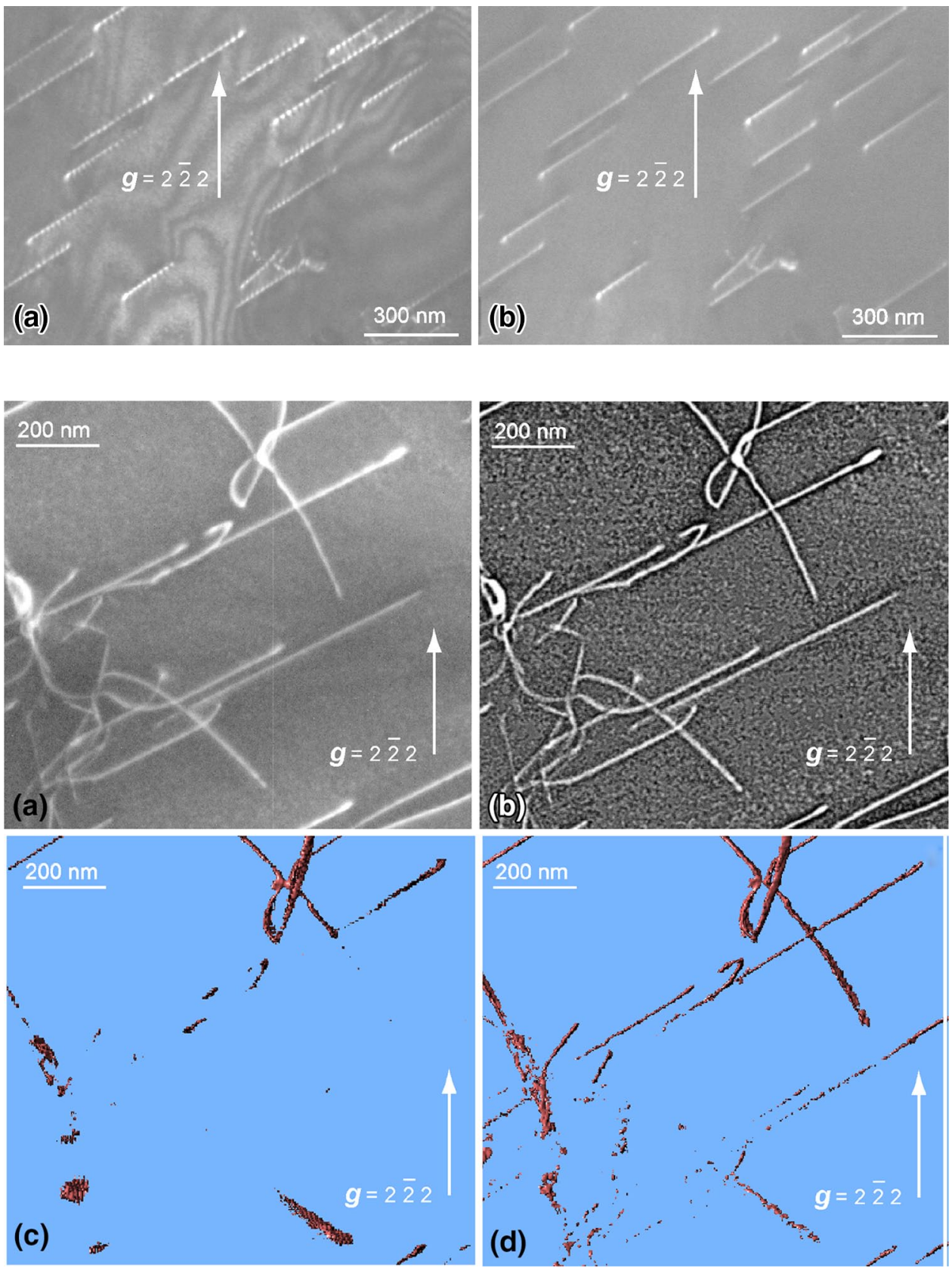
inclined dislocations. Figure 6 gives an example of the precession effect on the dislocation contrast and background homogeneity.

To enhance the dislocation contrast, each image of the tilted series has been convoluted with a kernel matrix (Barnard et al. 2010). Figure $7 \mathrm{a}$ is obtained in WBDF conditions, associated with a $0.1^{\circ}$ precession angle, without a convolution with a kernel matrix. It is compared with Fig. 7b, for which a convolution with a kernel matrix has been applied. Thus, we can verify that the kernel highly increases the dislocation contrast. The resulting 3D reconstructions from the unfiltered images (Fig. 7c) and the filtered images (Fig. 7d) show that the kernel allows keeping most of the dislocation population details.

To the best of our knowledge, the present study represents the first investigation of the slip planes of [001] dislocations in a deformed olivine polycrystal. We have noted a majority of [001] dislocations gliding in $\{110\}$, whereas a dominant role of the (100) glide plane was expected (e.g. Gaboriaud et al. 1981). Our study highlights the contribution of glide of [001] dislocations in several other planes when olivine is deformed at $900{ }^{\circ} \mathrm{C}$ : (010), $\{120\}$ and $\{130\}$. It is also shown that some [001] dislocation lines belong to several glide planes demonstrating an easy ability for cross-slip under these conditions. This mechanism originally suggested for [100] glide in olivine (Poirier and Vergobbi 1978; Li et al. 2006) has been recently suggested for [001] glide as well (Faul et al. 2011; Raterron et al. 2007, 2009). It had, however, never been characterized so far.

\section{Conclusion and perspectives}

Electron tomography gives access to a 3D characterization of dislocations microstructures. We show here that this technique is very efficient to characterize glide planes of dislocations with accuracy. In the present study, we show that in a polycrystal of olivine deformed in the low-temperature regime [i.e. below $1,000{ }^{\circ} \mathrm{C}$ and with a predominance of [001] screw dislocations], electron tomography allows to verify the activation of previously reported (100), (010) and $\{110\}$ planes, and permits identification of new slip planes: $\{120\}$ and $\{130\}$. Furthermore, the detailed analysis of the geometry of dislocation lines makes it possible to characterize in details complex mechanisms such as cross-slip. This information is very important as an input parameter for the visco-plastic self-consistent modelling of crystal preferred orientation evolution of olivine-rich aggregates (Tommasi et al. 2000; Mainprice et al. 2005; Durinck et al. 2007; Castelnau et al. 2009, 2010) and thus for a better understanding of deformation mechanism of the Earth's uppermost mantle.
Acknowledgments A Marie Curie fellowship awarded to S.D. (PoEM: Plasticity of Earth Mantle, FP7-PEOPLE-20074-3-IRG, $\mathrm{N}^{\circ} 230748$-PoEM) supported this study. The TEM national facility in Lille is supported by the CNRS (INSU) and the Conseil Régional du Nord Pas de Calais, France. This work was supported by funding from the European Research Council under the Seventh Framework Programme (FP7), ERC grant N²90424-RheoMan.

Open Access This article is distributed under the terms of the Creative Commons Attribution License which permits any use, distribution, and reproduction in any medium, provided the original author(s) and the source are credited.

\section{References}

Arslan I, Tong JR, Midgley PA (2006) Reducing the missing wedge: high-resolution dual axis tomography of inorganic materials. Ultramicroscopy 106:994-1000

Bai Q, Kohlstedt DL (1992) High-temperature creep of olivine single crystals, 2 dislocation structures. Tectonophysics 206:1-29

Barber D J, Wenk HR, Hirth G, Kohlstedt DL (2010) Dislocations in minerals. In: Hirth JP, Kubin L (eds) Dislocations in Solids. Elsevier, Oxford, United-Kingdoms, 19:171-232

Barnard JS, Sharp J, Tong JR, Midgley PA (2006a) High-resolution three-dimensional imaging of dislocations. Science 313:319

Barnard JS, Sharp J, Tong JR, Midgley PA (2006b) Three-dimensional analysis of dislocation networks in $\mathrm{GaN}$ using weak-beam dark-field electron tomography. Phil Mag 86:4901-4922

Barnard JS, Eggeman AS, Sharp J, White TA, Midgley PA (2010) Dislocation electron tomography and precession electron diffraction: minimising the effects of dynamical interactions in real and reciprocal space. Phil Mag 90:4711-4730

Buseck PR, Dunin-Borkowski RE, Devouard B, Frankel RB, McCartney MR, Midgley PA, Pósfai M, Weyland M (2001) Magnetite morphology and life on Mars. Proc Natl Acad Sci USA 98:13490-13495. doi:10.1073/pnas.241387898

Castelnau O, Blackman DK, Becker TW (2009) Numerical simulations of texture development and associated rheological anisotropy in regions of complex mantle flow. Geophys Res Lett 36:L12304. doi:10.1029/2009GL038027

Castelnau O, Cordier P, Lebensohn RA, Merkel S, Raterron P (2010) Microstructures and rheology of the Earth's upper mantle inferred from a multiscale approach. C R Physiques 11:304-315

Chen S, Hiraga T, Kohlstedt DL (2006) Water weakening of clinopyroxene in the dislocation creep regime. J Geophys Res 111:B08203

Darot M, Gueguen Y (1981) High-temperature creep of forsterite single crystals. J Geophys Res 86:6219-6234. doi:10.1029/JB086iB $07 \mathrm{p} 06219$

Demouchy S (2010) Diffusion of hydrogen in olivine grain boundaries and implications for the survival of water-rich zones in the Earth's mantle. Earth Planet Sci Lett 295:305-313

Demouchy S, Schneider SE, Mackwell SJ, Zimmerman ME, Kohlstedt DL (2009) Experimental deformation of olivine single crystals at lithospheric temperatures. Geophys Res Lett 36:L04304. doi:10.1029/2008GL036611

Demouchy S, Tommasi A, Barou F, Mainprice D, Cordier P (2012) Deformation of olivine in torsion under hydrous conditions. Phys Earth Planet Int 202-203:56-70

Demouchy S, Mussi A, Barou F, Tommasi A, Cordier P (2013a) Visco-plasticity of polycrystalline olivine at high pressure and $900^{\circ} \mathrm{C}$ : fresh outcomes from high resolution EBSD and electron tomography. AGU Fall meeting, session T012

Demouchy S, Tommasi A, Ballaran TB, Cordier P (2013b) Low strength of Earth's uppermost mantle inferred from tri-axial 
deformation experiments on dry olivine crystals. Phys Earth Planet Inter 220:37-49

Demouchy S, Mussi A, Barou F, Tommasi A, Cordier P (2014) Viscoplasticity of polycrystalline olivine at high pressure and $900{ }^{\circ} \mathrm{C}$ : fresh outcomes from high resolution EBSD and electron tomography. Tectonophysics (in press)

Durham WB, Goetze C (1977) Plastic flow of oriented single crystals of olivine: 1 Mechanical data. J Geophys Res 82:5737-5753. doi: 10.1029/JB082i036p05737

Durham WB, Goetze C, Blake B (1977) Plastic flow of oriented single crystals of olivine: 2. Observations and interpretations of the dislocation structures. J Geophys Res 82:5755-5770. doi:10.102 9/JB082i036p05755

Durinck J, Devincre B, Kubin L, Cordier P (2007) Modeling the plastic deformation of olivine by dislocation dynamics simulations. Am Mineral 92:1346-1357

Evans B, Goetze C (1979) The temperature variation of hardness of olivine and its implication for polycrystalline yield stress. J Geophys Res 84:5505-5524. doi:10.1029/JB084iB10p05505

Faul UH, Fitz Gerald JD, Farla RJM, Ahlefeldt R, Jackson I (2011) Dislocation creep of fine-grained olivine. J Geophys Res 116:B01203

Gaboriaud RJ, Darot M, Gueguen Y, Woirgard J (1981) Dislocations in olivine indented at low-temperatures. Phys Chem Miner 7:100-104

Gueguen Y (1979) High temperature olivine creep: evidence for control by edge dislocations. Geophys Res Lett 6:357-360. doi:10.10 29/GL006i005p00357

Gueguen Y, Darot M (1982) Dislocations in forsterite deformed at a high-temperature. Philos Mag A 45:419-442

Hazen RM (1976) Effects of temperature and pressure on the crystal structure of forsterite. Am Mineral 61:1280-1293

Head AK, Humble P, Clarebrough LM, Morton AJ, Forwood CT (1973) Computed electron micrographs and defect identification. North-Holland Publishing Company, Amsterdam London

Jaoul O, Michaut M, Gueguen Y, Ricoult D (1979) Decorated dislocations in forsterite. Phys Chem Miner 5:15-19

Kohlstedt DL, Goetze C (1974) Low-stress high-temperature creep in olivine single crystals. J Geophys Res 79:2045-2051. doi:10.102 9/JB079i014p02045

Kohlstedt DL, Goetze C, Durham WB, Van der Sande J (1976) New technique for decorating dislocations in olivine. Sciences 191:1045-1046

Li L, Weidner D, Raterron P, Chen J, Vaughan M, Shenghua M, Durham B (2006) Deformation of olivine at mantle pressure using D-DIA. Eur J Mineral 18:7-19. doi:10.1127/0935-1221/2006/0018-0007

Mainprice D, Tommasi A, Couvy H, Cordier P, Frost DJ (2005) Pressure sensitivity of olivine slip systems and seismic anisotropy of earth's upper mantle. Nature 433:731-733

McCammon CA (2005) The paradox of mantle redox. Science 308:807-808

Midgley PA, Dunin-Borkowski RE (2009) Electron tomography and holography in materials science. Nature Mater 8:271-280

Miller WH (1839) A treatise on Crystallography. Cambridge, England, printed for J. and J.J. Deighton; London: J.w. Parker
Paterson MS (1970) A high pressure, high temperature apparatus for rock deformation. Int J Rock Mech Min Sci 7:512-517

Paterson MS (1990) Rock deformation experimentation. In: Duba AG, Durham WB, Handin JW, Wang HF (Editors), The brittleductile transition in rocks: the Head volume. Geophys. Monogr. Ser., AGU, Washington D.C., 59:187-194

Penczek P, Radermacher M, Frank J (1992) Three-dimensional reconstruction of single particles embedded in ice. Ultramicroscopy 40:33-53

Phakey P, Dollinger G, Christie J (1972) Transmission electron microscopy of experimentally deformed olivine crystals. In: H.C. Heard, I.Y. Borg and N.L. Carter (Editors), Flow and Fracture of rocks. Am Geophys Un Geophys Monogr Series. doi: 10.1029/ GM016p0117

Phillips PJ, Brandes MC, Mills MJ, De Graef M (2011a) Diffraction contrast STEM of dislocations: imaging and simulations. Ultramicroscopy 111:1483-1487

Phillips PJ, Mills MJ, De Graef M (2011b) Systematic row and zone axis STEM defect image simulations. Phil Mag 91:2081-2101

Poirier JP, Vergobbi B (1978) Splitting of dislocations in olivine, cross-slip-controlled creep and mantle rheology. Phys Earth Planet Inter 16:370-378

Raleigh CB (1968) Mechanisms of plastic deformation of olivine. J Geophys Res 73:5391-5406. doi:10.1029/JB073i016p05391

Raterron P, Wu Y, Weidner DJ, Chen J (2004) Low-temperature olivine rheology at high pressure. Phys Earth Planet Inter 145:149159. doi:10.1016/j.pepi.2004.03.007

Raterron P, Chen J, Li L, Weidner D, Cordier P (2007) Pressureinduced slip-system transition in forsterite: single-crystal rheological properties at mantle pressure and temperature. Am Mineral 92:1436-1445. doi:10.2138/am.2007.2474

Raterron P, Amiguet E, Chen J, Li L, Cordier P (2009) Experimental deformation of olivine single crystals at mantle pressures and temperatures. Phys Earth Planet Inter 172:74-83. doi:10.1016/j.pepi.2008.07.026

Rebled JM, Yedra L, Estrade S, Portillo J, Peiro F (2011) A new approach for 3D reconstruction from bright field TEM imaging: beam precession assisted electron tomography. Ultramicroscopy 111:1504-1511

Sharp JH, Barnard JS, Kaneko K, Higashida K, Midgley PA (2008) Dislocation tomography made easy: a reconstruction from ADF STEM images obtained using automated image shift correction. J Phys Conf Ser 126:012013

Tanaka M, Honda M, Mitsuhara M, Hata S, Kaneko K, Higashida K (2008a) Three-dimensional observation of dislocations by electron tomography in a silicon crystal. Mater Trans 49:1953-1956

Tanaka M, Higashida K, Kaneko K, Hata S, Mitsuhara M (2008b) Crack tip dislocations revealed by electron tomography in silicon single crystal. Scripta Mater 59:901-904

Tommasi A, Mainprice D, Canova G, Chastel Y (2000) Viscoplastic self-consistant and equilibrium-based modeling of olivine lattice preferred orientations: implications for the upper mantle seismic anisotropy. J Geophys Res 105:7893-7908 